\title{
Success of the Tutorial Program in Biochemistry at The Federal University of Viçosa
} (UFV): Motivation and Leveling off Associated with New Learning Approaches

\author{
Baracat-Pereira, M.C. ${ }^{1,2}$; Sartori, M.A. ${ }^{1}$; Mendes, F.Q. ${ }^{1,}$; Carvalho, A.M.X. ${ }^{1}$; Dias, A.S. ${ }^{1}$; Ganda, T. ${ }^{1}$; \\ Pereira, H.J.V. ${ }^{1}$; Mendonça, M.A.C. ${ }^{1}$; Paiva, V.R. ${ }^{1}$; Braathen, P.C. ${ }^{1,3}$ \\ ${ }^{1}$ Programa de Tutoria, ${ }^{2}$ Depto. Bioquím. Biol. Molecular, ${ }^{3}$ Depto. Química, UFV, Viçosa, MG.
}

Institutionalized at UFV in 2001, the Tutorial Program in Biochemistry aims to reduce the unevenness of basic prior knowledge among the students enrolled in regular Biochemistry courses. The work methodology has been periodically evaluated and refined in order to overcome identified problems. Thus, the objective of this study was to evaluate the Tutorial Program based on the studentsáchievement, to show implemented modifications and proposed alternatives to adjust methodologies. The student-final-grades were obtained from UFV files. Questionnaires were applied to the Programs students at the end of each semester. Suggestions and criticism from tutors and coordinating professors were discussed at weekly meetings. Along six semesters (2001-2003), a leveling off of the tutorial students was observed with the attending students (S, minimum of $75 \%$ attendance, average grade 71.3) that got grades close to the average of no-tutorial students (average grade 71.5). For the tutorial students with attendance below the required minimum $(\mathrm{N})$, the average grade was 58.8. The failure rate for grade S students $(7.4 \%)$ was lower then that for no-tutorial students $(9.9 \%)$ and for grade N students (27.9\%). Based on the filled out questionnaire from tutorial students, we observe as follows: $96.7 \%$ stated that it is effective to participate in the Program and $79.9 \%$ modified their study approach. Among the modifications implemented in the Program, are as folows: 1) Increase in the number of tutorial groups (from 4 to 6); 2) Reduction in the number of volunteer-students, giving priority to students with deficient prior knowledge in pre-requisite-disciplines; and 3) Time reduction of tutorial sessions (from 3 to $2 \mathrm{~h}$ weekly), with smaller groups and exercise classes. Thus, the observed motivation, the leveling off and the lower failure rate of the $\mathrm{S}$ grade tutorial students indicated that the Tutorial Program at UFV is improving and reaching its objectives. Supported by: UFV, MEC. 